\title{
El binomio miseria-enfermedad: un estudio sociohistórico y legislativo sobre las fiebres tifoideas en España (1886-1930) desde la Historia de la salud
}

\section{The misery-disease binomial: a socio-historical and legislative study on typhoid fevers in Spain (1886-1930) from de History of health}

\section{O binômio miséria-doença: um estudo sócio-histórico e legislativo sobre a febre tifóide na Espanha (1886-1930) da História da saúde}

\author{
María Rosa Gómez Martínez ${ }^{1}$ \\ ${ }^{1}$ Doctora en Sociología por la Universidad de Alicante. Universidad de Murcia. Correo electrónico: \\ mariarosa.gomez@um.es
}

Cómo citar este artículo en edición digital: Gómez Martínez, M.R. (2020). El binomio miseria-enfermedad: un estudio sociohistórico y legislativo sobre las fiebres tifoideas en España (18861930) desde la Historia de la salud. Cultura de los Cuidados (Edición digital), 24 (56) Recuperado de http://dx.doi.org/10.14198/cuid.2020.56.07

Correspondencia: C/Mariano Benlliure, 29, 7º-2, 03201 Elche (Alicante). Correo electrónico de contacto: mariarosa.gomez@um.es Recibido:08/10/2019 Aceptado:09/01/2020

\section{ABSTRACT}

Typhoid fever is a disease that maintains a social character throughout the 20th century, related to wars and economic inequalities. It was the subject of a legislative response from the State, which from the end of the 19th century until 1930, systematized science against typhoid fevers and their vaccination in the form of large campaigns whose result was the progressive decrease in incidence, morbidity and mortality until its eradication practice. The research that concerns us refers to a sociohistorical and legislative study of the disease until the late 20s of the 20th in Spain.

Key Word: Typhoid fever, social disease, health legislation, health history, miserypoverty binomial.

\section{RESUMEN}

La fiebre tifoidea es una enfermedad que mantiene a lo largo del siglo XX un carácter social, relacionado con las guerras y las desigualdades económicas. Fue objeto de una respuesta legislativa del Estado, que desde finales del siglo XIX hasta 1930, sistematizó la ciencia contra las fiebres tifoideas y su vacunación en forma de grandes campañas cuyo resultado fue la progresiva disminución de incidencia, morbilidad y mortalidad hasta su práctica erradicación. La investigación que nos ocupa se refiere a un estudio sociohistórico y legislativo de la enfermedad hasta finales de los años 20 del siglo XX en España.

Palabras clave: Fiebre tifoidea, enfermedad social, legislación sanitaria, historia de la salud, binomio miseria-enfermedad. 


\section{RESUMO}

A febre tifóide é uma doença que mantém caráter social ao longo do século $\mathrm{XX}$, relacionada a guerras e desigualdades econômicas. Foi objeto de uma resposta legislativa do Estado, que desde o final do século XIX até 1930, sistematizou a ciência contra a febre tifóide e sua vacinação na forma de grandes campanhas cujo resultado foi a diminuição progressiva da incidência, morbidade e mortalidade até sua prática de erradicação. A pesquisa que nos preocupa refere-se a um estudo sócio-histórico e legislativo da doença até o final dos anos 20 do século XX na Espanha.

Palavras chave: Febre tifóide, doença social, legislação em saúde, histórico em saúde, binômio miséria-doença.

\section{INTRODUCCIÓN}

Si algo definió el concepto de progreso desde el punto de vista occidental en la salud pública fue la lucha contra las enfermedades infecciosas. La coyuntura que vivió Europa entre el Congreso de Berlín y el Tratado de Versalles (1884-1919), marcó un tiempo y un espacio crucial: el Instituto Pasteur y el de Albert Koch produjeron el gran desarrollo de la bacteriología y el eje franco-alemán monopolizó el auge de la vacunología y la serología en todo el mundo.

No obstante, el análisis de ese "kairós” de la vacunología sólo es posible si tenemos en cuenta las cuatro grandes revoluciones que determinaron el contexto de la lucha contra las enfermedades infecciosas (peste, cólera o difteria entre otras): en primer lugar, la revolución industrial, que generó un movimiento capital suficiente como para financiar los proyectos de investigación; en segundo, la revolución urbana, es decir, las concentraciones de población en las ciudades, cuyo crecimiento se produjo a marchas forzadas y marcado por la proletarización, la miseria y depauperación de inmensas masas de población; en tercer lugar, el proceso de construcción de los Estados, con importantes aparatos políticoadministrativos sanitarios; y por último, la revolución pasteuriana, que, como producto y respuesta a las tres primeras condiciones, supuso un cambio radical de paradigma en el momento en que se descubrieron los mecanismos infecciosos y se perfeccionó la vacuna.

La fiebre tifoidea es una enfermedad relacionada con condiciones de vida precarias. Por tanto, igual que la tuberculosis o el cólera, hemos de observar su análisis desde una perspectiva social, de modo que podemos definir estas infecciones como “enfermedades de clase”. Así lo advierte el historiador Jordi Nadal, "las enfermedades infecciosas se presentan, en el siglo XIX, como enfermedades sociales típicas. La inexistencia o la ineficacia de la actuación pública que ayude a combatirlas contribuye a reforzar el carácter discriminador que las distingue. La infección hace estragos entre las clases bajas y deja bastante incólumes a los núcleos privilegiados” (Nadal, 1988:158-159). La pobreza es sinónimo de enfermedad, y el pobre se convierte en el "vector" clave para su transmisión. Ya en 1790 el médico Johann Peter Frank (1745- 
Revista científica de la Asociación de Historia y Antropología de los Cuidados (Universidad de Alicante)

1821) en System einer vollsttindigen legislativo que vincula la enfermedad a nivel medizinischen Polizei (1779-1827) acuña el lema: "la miseria de los pueblos es la madre de las enfermedades” (Gómez Martínez, 2018:41); como indicaba el semanario Blanco y Negro en un artículo sobre el carnaval infantil de 1895: “todas esas mujeres andrajosas que os esperan a la puerta con el pretexto de pediros una limosna aguardan a vuestros hijos. Son la difteria, la escarlatina, la meningitis” (Blanco y Negro, 23-02-1895:13). Por tanto, cabe interpretar las enfermedades infectocontagiosas como amenaza social y económica, de ahí las políticas de control y vigilancia desde la administración estatal; se llega incluso a señalar a las enfermedades como de “plaga social” (Galiana; BernabeuMestre, 2006:144). En España, fue el Real Decreto de 10 de enero de 1919 el que reguló dicha obligatoriedad, que calificaba de “infecciones comunes” la difteria y las fiebres tifoideas (Gaceta de Madrid, 23-011919:9). El hecho de que se trate de enfermedades sensibles a las decisiones políticas, e incluso policiales, dota al cólera, la viruela, la tuberculosis, la difteria o las fiebres tifoideas de un decisivo valor sociohistórico y cultural donde el binomio miseria-enfermedad es su más claro exponente tratándose, como expone Monge (2018:32), de hechos glocales.

\section{OBJETIVOS}

Un primer objetivo trata de mostrar un modelo de análisis sociohistórico y

\section{METODOLOGÍA}

El método utilizado en este estudio es el hipotético-deductivo iniciando una búsqueda bibliográfica sobre las fiebres tifoideas en España desde el punto de vista de la sociología narrativa y la prensa histórica como vehículo preferente, "recreando una realidad que está social y culturalmente constituida” (Burque, 1996:15) y requiriendo de una “descripción densa” que desentrañe los matices más 
significativos de los hechos históricos que se muestran ante el investigador (Geertz, 1990:21). Una hermenéutica narrativa que permite "la comprensión de la complejidad psicológica de las narraciones que los individuos hacen de los conflictos y los dilemas en sus vidas” dando sentido $\mathrm{y}$ comprendiendo frente a la explicación causas-efectos (Bolívar, 2002:5).

\section{LAS FIEBRES TIFOIDEAS}

Andrew Johnson (1808-1875) se convirtió en presidente de los Estados Unidos de América tras el asesinato de Lincoln. Durante su ceremonia de investidura, Johnson presentó visibles muestras de embriaguez. El escándalo adquirió tales proporciones que el nuevo presidente se vio obligado a explicar que había tomado alguna cantidad de licor, bajo prescripción médica, ya que padecía fiebres tifoideas ( $A B C, 10-01-1899: 40)$. En 1865 se sabía muy poco sobre la etiología o el tratamiento de las fiebres tifoideas, pero desde el final de aquella década, hasta los últimos años del siglo XIX, la ciencia puso cerco a esta infección y dio con varias vacunas efectivas.

Las fiebres tifoideas, entéricas, paratifoideas, paratíficas, tifus abdominal, intestinal, salmonelosis o fiebres tifoideas en general son enfermedades infecciosas septicemias- (Arbelo, 1966:49) de carácter epidémico, producidas por una bacteria del género salmonella typhi o paratyphi $\mathrm{A}, \mathrm{B}$ o C. En 1880 el patólogo y bacteriólogo alemán Karl Joseph Eberth (1835-1926)

descubrió este agente causante, también llamado bacilo de Eberth o Eberthella, aunque la denominación genérica “salmonelosis" se debe al veterinario estadounidense Daniel Elmer Salmon (18501914).

Las fiebres tifoideas hallaron su tasa de morbilidad y mortalidad más elevada durante la segunda mitad del siglo XIX, sobre todo en episodios bélicos, como la Guerra de Crimea (1853-1856), la FrancoPrusiana (1870-1871), la tercera Guerra Carlista (1874-1876) en Europa, la de Secesión (1860-1865) en Estados Unidos, la de Cuba, las de la Anglo- Boer (1899-1902) (Cirillo, 2013: 2-8) en África o la Gran Guerra (1914-1918), en todo el mundo (Hardy, 2000), pero también, en las áreas urbanas e industrializadas de mayor concentración demográfica, allí donde el desempleo y la miseria se propagaban a marchas forzadas. Destaca el caso de Madrid en 1886, Barcelona en 1892 (Martínez Vargas, 1915) o Chicago, a principios de la década de 1890. No obstante, la presencia del bacilo de Eberth en zonas rurales fue también muy significativa, sobre todo en España (Palanca, 1929). Es decir, el nervio de la fiebre tifoidea no fue otro que "la ignorancia, la inmundicia, la pobreza, la falta de higiene, los movimientos de población y la mala organización sanitaria y las guerras” (Tuells, 2009: 64-67) en una clara relación con los Determinantes Sociales de la Salud (DSS), "aquellas circunstancias en que las personas nacen, crecen, viven, trabajan y 
Revista científica de la Asociación de Historia y Antropología de los Cuidados (Universidad de Alicante)

envejecen, incluido el sistema de salud. Estas circunstancias son el resultado de la distribución del dinero, el poder y los recursos a nivel mundial, nacional y local, que depende a su vez de las políticas adoptadas" (OMS). De esta manera "la salud se gana o se pierde, ahí donde el hombre nace, trabaja, se recrea y también ama” (Fuentes-Tafur, 2009: 371).

\section{LA CONTROVERSIA DE UNA CONFUSIÓN: TIFUS VERSUS} FIEBRES TIFOIDEAS Y LA VACUNA WRIGHT-PFEIFFER

Advierte José Tuells que la fiebre tifoidea es ejemplo de una ceremonia de la confusión "ubicada en diversas clasificaciones semiológicas a la vez” a lo que hemos de sumar el tiempo que transcurrió hasta que la enfermedad "pudo encontrar su propia entidad nosológica” (2009: 64).

Tras una epidemia en París, Pierre Louis (1787-1872), fue el primero en definir la fiebre tifoidea en un ensayo titulado "Recherches anatomiques, pathologiques et thérapeutiques sur la fièvre typhoïde”, que vio la luz en 1829, aunque la verdadera distinción respecto al tifus exantemático la debemos a Sir William Jenner (1815-1898), hacia 1849 (Tuells, 2009: 65). A su vez, el también británico Charles Murchison (1830-1879) rompió con la vieja teoría de la “generación espontánea” y pretendió demostrar que la etiología de las fiebres tifoideas se encontraba en la inhalación o ingestión de sustancias pútridas o fecales (Ledermenn, 2003:58), hipótesis a la que contestaría William Budd (1811-1880), precursor de la epidemiología, con la conjetura del "principio específico", que desarrolló en su obra "Tiphoid fever", publicada en 1873 (Tuells, 2009:66). Finalmente, esta carrera por la caza del agente causante culminó en dos momentos: en 1880, cuando Karl Joseph Eberth, después de varias docenas de autopsias, identificó el bacilo, y en 1884, cuando el discípulo de Robert Koch (1843-1910), Georg Gaffky (1850-1918) fue capaz de aislar y cultivar el microbio, paso previo para el descubrimiento de una vacuna (Tuells, 2009:66). Poco después, hacia la segunda mitad de la década de los 90, Hugo Schottmüller (1867-1936), Albert Brion y Heinrich Kayser clasificaron el bacilo paratifoideo en dos grupos que denominaron A y B (Tuells, 2009:66). Pero tras este descubrimiento, surgió una nueva controversia en la historia de la lucha contra el bacilo de Eberth, ya que en 1896 dos vacunólogos, el británico Almrouth Wright (1861-1947) y el alemán Richard Pfeiffer (1858-1945) descubrieron, de forma simultánea, la vacuna contra la fiebre tifoidea (Tuells, 2009:66). Parece demostrado que los dos llegaron a la misma conclusión y, lo más importante, ambos investigadores aportaron una nueva vía alternativa a la de Pasteur, el uso de 
gérmenes inactivados por calor en una

vacuna (Tuells, 2009:66).

Durante los años posteriores, la vacuna de Wright demostró su eficacia, sobre todo en el ámbito militar, ya que las campañas se efectuaron en el ejército británico, francés o alemán. Poco después, hacia 1910, también el epidemiólogo galo Hyacinthe H. Vincent (1862-1950) elaboró en una vacuna contra las fiebres tifoideas y paratifoideas de tipo A y B, suero que se aplicó con éxito durante la I Guerra Mundial en el ejército francés.

\section{LAS FIEBRES TIFOIDEAS $Y$ PARATÍFICAS EN ESPAÑA}

El 18 de junio de 1878, a la joven María de las Mercedes de Orleans y Borbón se le presentaron unas calenturas altísimas acompañadas de hemorragias intestinales. Los médicos supieron pronto que se trataba de fiebres tifoideas y que no había nada que hacer para salvar la vida de la esposa del rey de España. Apenas una semana después, el 25 de junio, cuentan las crónicas que en Madrid se cerraron cafés y teatros, y a las doce horas y cinco minutos del día del siguiente, Doña María de las Mercedes murió en su lecho del Palacio Real. Las fiebres tifoideas habían cobrado su tributo en la vida de la reina, igual que habrían de continuar su camino de muerte, sobre todo entre los más pobres de Madrid, Barcelona u otras ciudades.

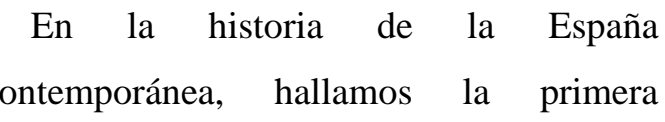

referencia a las fiebres tifoideas en un texto en la Gaceta de Madrid el 14 de febrero de 1836. Se trata de un breve párrafo que prevenía a los ciudadanos del peligro que en aquella época del año entrañaban "las calenturas tifoideas, cólicos, anginas y reumas” (Gaceta de Madrid, 14-02-1836:4). Hasta aquel momento, parece ser que no se detectó presencia significativa de esta enfermedad, de la que no volvemos a tener noticia en la Gaceta hasta 1845, en una efímera alusión a la presencia de "calenturas tifoideas" en algunos reclusos de la cárcel de Sevilla (Gaceta de Madrid, 10-03-1845:2).

Tras estas referencias, se pierde la pista de las tifoideas, hasta la muerte de la esposa de Alfonso XII. Los casos de infectados empezaron a abundar, y la enfermedad fue adquiriendo cierta dimensión social. En 1881, La Vanguardia, en el contexto de algunos descubrimientos sobre enfermedades tropicales, reproducía: “En bien de la humanidad conviene que se propaguen estos descubrimientos, que tal vez servirán para combatir también eficazmente las epidemias de tifoideas, cólera y otras” (24-07-1881:3764). La alusión nos sitúa ante un panorama urbano, en el que las fiebres tifoideas empezaban a ocupar un lugar notable. Es el primer momento de una serie de epidemias recurrentes en Madrid, Barcelona, o Valencia, sin olvidar los estragos que ya venían dejando su luctuoso rastro en una España rural en crisis, mal alimentada y mal asistida desde el punto de vista sanitario. 
Revista científica de la Asociación de Historia y Antropología de los Cuidados (Universidad de Alicante)

La presencia de las fiebres tifoideas fue ya una constante en la sociedad española desde principios de la década de los 80. Así lo demuestra de nuevo La Vanguardia, que en julio de 1885 citaba los casos de muerte por fiebres tifoideas en la ciudad condal, que alcanzaban un $2,7 \%$ del total de fallecidos (07-06-1885:3659), solo unos meses después, en diciembre, el lenguaje periodístico se recrudecía, definiendo a la tifoideas como "una marcha invasora”, ya que la cifra de defunciones asciende a un 7\% (05-12-1885:7800). Fue a partir de la segunda mitad de los años 80 cuando la fiebres tifoideas quedaron insertadas en la cultura sanitaria de la prensa $-L a$ Vanguardia, La Iberia-, cultura que se reflejó en la publicidad semanal, como es el caso de la del Instituto Médico Celular y Antiséptico del Dr. Audet, que anunciaba "tratamientos especiales contra las enfermedades infecciosas” entre las que se encontraba la fiebre tifoidea (24-01-1889 y 26-03-1899). Aunque la primera referencia que hemos encontrado a Bacilo de Ebert como tal, es de febrero de 1912, y se define como "propagador del tifus" (ABC, 12-021912:12).

\section{LA LUCHA CONTRA LAS FIEBRES TIFOIDEAS EN ESPAÑA (1886-1930)}

Como ocurrió en el resto de Europa, el fenómeno epidémico de las fiebres tifoideas o paratíficas en España -igual que la difteriacoincidió con el gran desarrollo urbano de
Madrid, Barcelona o Valencia, también con el de la aparición de una "nueva pobreza”, y con el de los grandes movimientos migratorios que facilitó el ferrocarril en la península. La prensa abundaría en la queja por las malas condiciones sanitarias de Madrid, tal es el caso del reportaje titulado "La salud pública”, aparecido en la revista Blanco y Negro (23-09-1899:12), que, en el contexto de la epidemia de peste de Oporto, en el mes de septiembre, denunciaba el "hacinamiento en que vive la clase pobre en las llamadas casas de vecindad”. Además, llegado el siglo XX, era frecuente la publicación de pequeños reportajes informativos en los que los periódicos o revistas se proponían educar y prevenir a las madres (ABC, 01-06-1908:13): "Las enfermedades del aparato digestivo, acompañadas de vómitos, fiebres o diarreas, son casi siempre muy dignas de atención en los niños. Las llamadas gástricas son por lo común tifoideas de mediana intensidad...”.

La idea de fiebre tifoidea se había introducido en la mentalidad colectiva de los españoles y a veces, hasta se identificaba con los males políticos, tal es el caso del periodista de la época, Luis Taboada (18481906) que comparaba los estragos de las fiebres tifoideas con las políticas de Antonio Maura (ABC, 26-06-1903:6).

Las tifoideas se habían consolidado como una amenaza social latente y, aunque no alcanzaron la magnitud del cólera, sí dejaban notar su rastro de muerte en los 
barrios más populosos de Madrid o

Barcelona. El 31 octubre de 1886, La Gaceta (304:328) publicó una circular emitida por el Ministerio de la Gobernación en la que se daba noticia de los “estragos” que las fiebres tifoideas estaban produciendo en "algunas localidades”. La circular era un recuerdo de la Real Orden de 22 de septiembre del mismo año de medidas contra la epidemia de difteria, a la que se añadían las fiebres tifoideas.

Las fiebres tifoideas se habían convertido en una enfermedad endémica entre 1886 y 1924 en toda España, con episodios epidémicos, como el de 1886-88, 1899, 1905, que coincide con un rebrote de viruela y tuberculosis (ABC, 19-06-1905:6), 1907 en Cartagena ( $A B C$, 25-04-1907:4), el de 1909, que en Madrid, entre febrero y noviembre (ABC, 07-02-1909:7-8; 18-02:7; 01-03:7; 15-03:7; 25-03:9; 04-05:7; 10-05:14; 3005:5; 05-07; 19-07:12; 08-08:12; 06-09:12; 17-10:16; 15-11:15 ), se complicó con sarampión y tifus exantemático ( $A B C, 22-$ 02-1909:6), la epidemia de Valencia, durante la Exposición Regional, también de 1909 (ABC, 24-12:14), pero sobre todo, la de Madrid, Barcelona y Vigo en 1913-14, y la de 1923-24, ésta última de especial virulencia en Madrid. Los informes españoles reflejan "graves problemas asociados a la pobreza” y a las deficientes infraestructuras de higiene pública en relación con enfermedades respiratorias, infecciones infantiles o de transmisión hídrica; Rodríguez habla de la “enfermedad de la miseria” por las consecuencias nocivas de la industria (2005:150). La epidemia de Madrid, de 1913 produjo la primera campaña de vacunación contra las fiebres tifoideas, impulsada por Manuel Martín Salazar (1854-1937), junto a Antonio Gadea Pro (1861-1928) y César Chicote y del Riego (1861-1950), en la que se llegó a inmunizar a 478 personas cuyas edades oscilaban entre los 8 y los 50 años, también la primera Real Orden circular de 2 de julio en la que se recomendaba el uso de la vacuna antitífica “en todo el territorio en tiempo de epidemias o de recrudecimiento de las endemias, singularmente entre las grandes colectividades, y en particular en el ejército y la Armada” (Gaceta de Madrid, 18-071913:129-130). Las inferencias de esta campaña, según Chicote fueron tres: que se debía organizar una campaña con "vacuna preventiva”; que se debía “decretar como obligatoria” en casos epidémicos; y que convenía seguir estudiando la “acción terapéutica” de dicha vacuna (Chicote, 1915:741). El caso de Vigo fue también muy importante, ya que Martín Salazar, que era en aquellos momentos buen conocedor de los avances científicos que se estaban produciendo en Europa o Estados Unidos era Director General de Sanidad Exterior (1909-1916)-, tras la experiencia de Madrid, dirigió una campaña de vacunación contra las fiebres tifoideas sobre población civil que, hasta aquel momento, fue la más intensa y sistematizada de España, y cuyas conclusiones presentó en un interesante artículo titulado "Estado actual de la vacuna antitífica”, publicado en 1915. En este 
Revista científica de la Asociación de Historia y Antropología de los Cuidados (Universidad de Alicante)

artículo el especialista sevillano analizó las respuestas satisfactorias ante vacunas procedentes de laboratorios muy distintos, como el del Instituto Alfonso XIII, el Municipal de Madrid, de Londres, u otros, pero sobre todo, sintetizaba su visión de las tres vacunas que, hasta los años de la I Guerra Mundial, se habían experimentado sobre población militar en Europa y América: la de Pffeifer, la de Wright y la de Vincent (Salazar, 1915). En 1912, Martin Salazar había publicado una de sus obras más importantes, "La lucha contra las fiebres tifoideas”, en la que exponía definitivamente que la etiología de la enfermedad residía en el agua y en alimentos en mal estado. Por ello, debido a la influencia de Martín Salazar, a partir de 1908, el Ministerio de la Gobernación y de Fomento emprendieron una intensa actividad legislativa que tuvo por objeto el desarrollo de saneamientos y gestión de aguas potables. El Real Decreto de 22 de diciembre de 1908 regulaba las condiciones que habían de cumplir "todas las aguas destinadas a la alimentación” (Gaceta de Madrid, 23-12-1908:1182-1186) y la Real Orden de 30 de mayo de 1914 volvía a incidir en las condiciones del agua potable de los municipios (Gaceta de Madrid, 04-06-1914:609-610). Un estudio realizado por la Academia de Higiene de Cataluña situaba las "deficiencias relacionadas con el ciclo del agua entre los principales determinantes de la salud de los catalanes” que carecían de alcantarillado en un $70 \%$ de los municipios y de agua potable en el 49\% de ellos. (Galiana; Bernabeu-

Mestre, 2006:151).

Después del golpe de Estado de Primo de Rivera, el directorio militar orienta su política sanitaria y reformista hacia el control y captación de aguas potables, tanto en áreas urbanas como rurales, siguiendo el modelo italiano de la Ley de 14 de julio de 1885 por la que el Estado se comprometía al abastecimiento de agua potable a todas las poblaciones de más de 10.000 habitantes y para lo que se construye el acueducto de Puglia (Palanca, 1929:83). Esta gestión de las aguas potables recayó definitivamente en los municipios, en virtud del Real Decreto de 9 de febrero de 1925 que publicaba el Reglamento de Sanidad Municipal (Gaceta de Madrid, 17-02-1925:726-728). Tal es el caso de la ciudad de Elche que en 1925 "tiene aguas potables pero en cantidad inferior de veinte litros por habitante y día que señala el reglamento municipal, no tiene alcantarillado que reúna condiciones higiénicas y existen aguas estancadas y charcas” (Correspondencia, d/154:1925, AHME). El semanario Levante afirmará en su artículo “Aguas potables” en 1926 que "las aguas de Elche son salobres, malas, hasta el extremo de no servir para cocer legumbres”.

Tras este periodo crítico (1886-1924), desde el punto de vista económico, social y epidémico, los años 20 y 30 en España, sobre todo después de 1924, se tradujeron en una 
progresiva caída de las infecciones y

fallecimiento por fiebres tifoideas, que en 1936, había descendido un 51,8\%. Aunque la vacunación nunca fue masiva, ni las tifoideas fueron objeto principal de las autoridades sanitarias españolas, hemos de atribuir esta evolución positiva desde los primeros años 20 a un momento de cierta bonanza económica y social en España que afectó a todas las enfermedades infecciosas. En el caso de la ciudad de Elche los casos de fiebres tifoideas constatados entre 19301931 son escasos en relación con otras enfermedades como el sarampión o la gripe (Comunicación, d/163, 30-06-1930; d/162, 05-09-1930; d/164/2, 05-02-1931; d/164/2, 04-05-1931; AHME). También es considerable el hecho de que las fiebres tifoideas fueran incluidas en el grupo B - de “infecciones comunes”- de la lista de "enfermedades de declaración obligatoria”, a partir de 1919 en el Real Decreto de 10 de enero. No obstante, las fiebres tifoideas siguieron siendo un problema social, así lo manifestaba en 1929 el futuro director general de sanidad, José Alberto Palanca (1888-1973), que consideraba las fiebres tifoideas como un problema sin resolver atribuido a tres causas: la mala gestión de las aguas potables por municipios $\mathrm{y}$ diputaciones provinciales; la falta de una educación higiénica suficiente; y las malas “condiciones de habitación” de la mayoría de los españoles (Palanca, 1929:9). El advenimiento de la II República supuso avances sociales y educativos que contribuirían al drástico descenso de la enfermedad. Durante ésta década de los años treinta, el Instituto Llorente, desarrolló la primera estandarización de una vacuna polivalente contra la fiebre tifoideaparatífica, antiestafilocócica, antigonocócica y antimelitense (Mateo de la Hoz, 2016:172).

\section{CONCLUSIONES}

La fiebre tifoidea es una enfermedad directamente relacionada con el desarrollo social de una población, por tanto, su análisis implica una perspectiva desde la historia económica, social, política y legislativa en el marco de la Historia de la Salud.

El desarrollo de esta enfermedad infecciosa tuvo lugar entre la década de los años 80 del siglo XIX y los primeros años 20 del siglo $\mathrm{XX}_{2}$ y es el producto del proceso de proletarización de la sociedad española, sobre todo en las grandes ciudades -Madrid, Barcelona o Valencia-.

Las primeras medidas legales contra las fiebres tifoideas se dieron entre 1886 y 1890 , de entre las que destaca la Orden del 22 de septiembre de 1886 y la de 12 de agosto de 1888, como respuesta a la epidemia de Madrid y Barcelona, y tuvieron un carácter preventivo, similar a las estrategias conocidas en aquel momento contras las epidemias de cólera: propuestas higiénicas y destinadas a desactivar los posibles focos de infección.

La vacuna contra las fiebres tifoideas fue introducida en España en 1913 por Manuel Martin Salazar, y las primeras campañas 
Revista científica de la Asociación de Historia y Antropología de los Cuidados (Universidad de Alicante)

sistematizadas contra el Bacilo de Eberth se experimentaron durante la epidemia de Madrid en 1913, y sobre todo, en Vigo, en 1914. Fueron dirigidas por Martín Salazar, que conocía las tres vacunas que hasta aquel momento existían, la de Wright, la de Pffeifer y la de Vincet.

En 1919, el Real Decreto de 10 de enero incluyó las fiebres tifoideas en la lista de enfermedades de obligatoria declaración, siguiendo el modelo de políticas sanitarias públicas francés. Tal y como había ocurrido en Italia o Bélgica, entre 1914 y 1925 el Ministerio de Fomento inició en España una intensa actividad legislativa contra las fiebres tifoideas $\mathrm{y}$ tuvo por objeto el desarrollo de saneamientos y gestión sanitaria de aguas potables.

A partir de los primeros años 20, como resultado de la buena coyuntura económica nacional y de la mejora de las condiciones de vida, las fiebres tifoideas empezaron a reducir sus cifras de morbilidad $\mathrm{y}$ mortalidad, hasta 1936, año en que se alcanzan las mejores estadísticas. Por último, destacar que, en la historia de la lucha contra las fiebres tifoideas nada tendría sentido sin la influencia de Vicente Llorente y Matos y Manuel Martín Salazar.

\section{BIBILIOGRAFIA Y FUENTES}

Arbelo, A. (1966). Pediatría preventiva antiinfecciosa en España. Madrid: Ministerio de Trabajo, Instituto Nacional de Previsión. Ciudad Sanitaria de la Seguridad Social "La Paz".
Bolívar Botía, A. (2002). ¿De nobis ipsis silemus?. Epistemologia de la investigación biográfico-narrativa en educación. Revista Electrónica de investigación educativa, 4(1), 1-26. Recuperado de https://redie.uabc.mx

Burque, P. (1996). Formas de hacer historia. Madrid: Alianza editorial.

Cirillo, V. J. (2013). Arthur Conan Doyle (1859-1930): Physician during the typhoid epidemic in the Anglo-Boer (1899-1902). Journal of Medical Biography, 22(1), 2-8.

Fuentes-Tafur, L. A. (2009). Enfoque sociopolítico para el control de la tuberculosis en el Perú. Revista Peruana de Medicina Experimental y Salud Pública, 26(3), 370-379.

Galiana, M. E.; Bernabeu-Mestre, J. (2006). El problema sanitario de España: saneamiento y medio rural en los primeros decenios del siglo XX. Asclepio. Revista de Historia de la Medicina y de la Ciencia. LVIII(2), 139-164.

Geertz, C. (1990). La interpretación de las culturas. Barcelona: Gedisa.

Gómez Martínez, M.R. (2018). Crónica de la pobreza. Orígenes de la Asistencia Social en una ciudad del mediterráneo. Elche, 19231930. Elche: Cátedra Pedro Ibarra, Universidad Miguel Hernández.

Hardy, A. (2000). Straight Back to Barbarism: Antityphoid Inoculation and the Great War, 1914. Bulletin of the history of medicine, 74, 265-290.

Ledermenn, W. D. (2003). Una historia del bacilo de Eberth desde Junker a Germanier. Revista Chilena de Infectología, 20, 58-61. 
Martínez Vargas, A. (1915). La última epidemia de fiebre tifoidea en Barcelona. Anales de la Real Academia de Medicina y Cirugía de Barcelona, 1, 18-27. Recuperado de

http://www.raco.cat/index.php/AnalesRA MC/article/viewFile/207570/290110.

Mateo de la Hoz, M. (2016). Historia del Instituto Llorente (1894-1997). (tesis doctoral en acceso abierto). Madrid: Facultad de Farmacia, Universidad Complutense de Madrid. Recuperado de https://dialnet.unirioja.es/servlet/tesis?co digo $=169868$

Monge Juárez, M. (2018). La epidemia de cólera morbo de 1884 en Elche; un elemento de cambio de sociedad y una nueva categoría de la contemporaneidad. Cultura de los cuidados (Edición digital), 22(51). Recuperado de http://dx.doi.org/10.14198/cuid.2018.51.0 4

Nadal, J. (1988). La población española (siglos XVI a XX). Barcelona: Ariel.

Organización Mundial de la Salud (OMS) (2009) Reducir las inequidades sanitarias actuando sobre los determinantes sociales de la salud. Recuperado de https://apps.who.int/gb/ebwha/pdf_files/ A62/A62_R14-sp.pdf?ua=1

Palanca, J. A. (1929). El problema de la fiebre tifoidea en España. Discurso leído en la Real Academia de Medicina el 9 de febrero de 1929. Madrid: Imprenta Gráfica Universal, . 9.

Salazar Martín, M. (1915). Estado actual de la vacuna antitífica. Real Academia de Medicina. Tomo XXXV. Cuaderno 2-3.
Tuells, J. (2009). El estupor de las fiebres confusas: tifoideas y vacuna de Almroth Wright. Vacunas. 10(2), 64-67.

Rodríguez Ocaña, E. (2005). Salud Pública en España. Ciencia, profesión y política, siglos XVIII-XX. Granada: Universidad de Granada.

\section{FUENTES PRIMARIAS}

\section{Prensa histórica}

$A B C, 10$ de enero de 1899, p. 40.

$A B C$, "La vida en broma. La temperatura y el gobierno", 26 de junio de 1903, p. 6.

ABC, "Notas médicas", 19 de junio de 1905, p. 6.

$A B C$, "La salud en Cartagena”, 25 de abril de 1907, p. 4.

$A B C$, "La madre y el niño", 1 de junio de 1908, p. 13.

$A B C, 7$ de febrero de 1909, pp.7-8

$A B C, 18$ de febrero de 1909, p. 7.

$A B C$, "La salud en Madrid”, 22 de febrero de 1909, p. 6.

$A B C, 1$ de marzo de 1909, p. 7.

$A B C, 15$ de marzo de 1909, p. 7.

$A B C, 22$ de marzo de 1909, p. 6.

$A B C, 25$ de marzo de 1909, p. 9.

$A B C, 4$ de mayo de 1909, p. 7.

$A B C, 10$ de mayo de 1909, p. 14.

$A B C, 30$ de mayo de 1909, p. 5

$A B C, 5$ de julio de 1909, p. 12.

$A B C, 8$ de agosto de 1909, p. 12.

$A B C, 6$ de septiembre de 1909, p. 12.

$A B C, 17$ de octubre de 1909, p. 16.

$A B C, 15$ de noviembre de 1909, p. 15.

$A B C, 24$ de diciembre de 1909, p. 14.

$A B C, 12$ de febrero de 1912, p. 12.

Blanco y Negro, "Los niños en carnaval”, 23 de febrero de 1895, p. 13.

Blanco y Negro, 23 de septiembre de 1899, p. 12.

Gaceta de Madrid, "Estado sanitario de Madrid", 14 de febrero de 1836, p. 4.

Gaceta de Madrid, "Sevilla 3 de marzo", 10 de marzo de 1845, p. 2.

Gaceta de Madrid, 23 de septiembre de 1886, 266. p.890. 
Gaceta de Madrid, 31 de octubre de 1886, 304. p. 328.

Gaceta de Madrid, 23 de diciembre 1908, 358, pp. 1182-1186.

Gaceta de Madrid, 18 de julio de 1913, 199, p. 129-130.

Gaceta de Madrid, 4 de junio de 1914, 155, pp. 609-610.

Gaceta de Madrid, 23 de enero de 1919, 23, p. 9.

Gaceta de Madrid, 17 de febrero de 1925, 48, p. 726-728.

La Iberia, diario liberal de Madrid, 26 de marzo de 1889.

La Vanguardia de Barcelona, 24 de julio de 1881, p. 3764.

La Vanguardia de Barcelona, 7 de junio de 1885, p. 3659.

La Vanguardia de Barcelona, 5 de diciembre de 1885, p. 7800.

La Vanguardia de Barcelona, 24 de enero de 1889.

Levante, PH-45, núm. 29 de 10 de Diciembre de 1926 (Archivo Histórico Municipal Elche - AHME).

\section{Otros documentos}

Comunicación d 163, de 30 de Junio de 1930 (AHME)

Comunicación d 162, de 5 de Septiembre de 1930 (AHME)

Comunicación d 164/2, de 5 de Febrero de 1931 (AHME)

Comunicación d 164/2, de 4 de Mayo de 1931 (AHME)

Correspondencia d 154, s/f. agosto de 1925 (AHME)

\section{DISCURSO}

LETDO EN LA

\section{Real Academia de Medicina}

\author{
PARA LA \\ RECEPCIÓN PÚBLICA DEL, ACADÉMICO ELECTO \\ Excmo. Sr. D. José A. Palanca
}

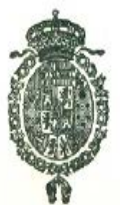

MADRID

ImPRENTA GrApica Universal

EYARISTO SAN MIGUII, 8

1929 


\begin{tabular}{|c|c|}
\hline \multicolumn{2}{|c|}{ SINOPSIS LEGISLATIVA DEL PERIODO SOBRE FIEBRES TIFOIDEAS } \\
\hline Fecha/Publicación & Descripción \\
\hline $\begin{array}{l}\text { 22-09-1886 } \\
\text { Gaceta de Madrid de } 22 \\
\text { de septiembre. } \\
\mathrm{N}^{\mathrm{a}} 266\end{array}$ & $\begin{array}{l}\text { Real Orden de } 22 \text { de septiembre por la que se dictan medidas contra la } \\
\text { epidemia de difteria según la Real Academia de Medicina y el Real } \\
\text { Consejo de Sanidad (se incluyen las fiebres tifoideas). }\end{array}$ \\
\hline $\begin{array}{c}\text { 30-10-1886 } \\
\text { Gaceta de Madrid de } 31 \\
\text { de octubre. } \\
\text { No }^{0} 304\end{array}$ & $\begin{array}{l}\text { Circular del } 30 \text { de octubre por la que se incorpora a la Real Orden del } \\
22 \text { de septiembre la “observación” contra las “calenturas tifoideas”. }\end{array}$ \\
\hline $\begin{array}{c}\text { 22-05-1895 } \\
\text { Gaceta de Madrid de } \\
25 \text { de mayo de } 1895 . \\
\text { NNo }^{\circ} 145\end{array}$ & $\begin{array}{l}\text { Real Decreto de } 22 \text { de mayo por la que se autoriza la creación del } \\
\text { Instituto Microbiológico en Madrid dirigido por el Doctor Vicente } \\
\text { Llorente y Matos, en los términos establecidos en la Real Orden del } 2 \text { de } \\
\text { marzo. }\end{array}$ \\
\hline
\end{tabular}

22-12-1908

Gaceta de Madrid de Real decreto del 22 de diciembre, por el que se dictan nomas de análisis

23 de mayo de 1908. de las aguas destinadas a consumo humano

$\mathrm{N}^{\circ} 358$

18-07-1913

Real orden circular de 2 de julio por la que se recomienda el uso de la

Gaceta de Madrid de 2 de julio de 1913. vacuna anti-tífica "en todo el territorio en tiempo de epidemias o de No 199 recrudecimiento de las endemias, singularmente entre las grandes 30-05-1914

Gaceta de Madrid de

31 de mayo de 1914.

$\mathrm{N}^{\mathrm{o}} 155$. colectividades, y en particular en el ejército y la Armada.”

Real Orden de 30 de mayo sobre el análisis de las aguas destinadas al abastecimiento en poblaciones” referida al Real Decreto de 22 de diciembre de 1908.

10-01-1919

Gaceta de Madrid de Real Decreto de 10 de enero por medio del cual las fiebres tifoideas son

23 de enero de 1919. de “obligatoria declaración”.

No 23.

9-02-1925

Gaceta de Madrid de Real decreto de 9 de febrero por el que se sanciona el Reglamento de

9 de febrero de 1925. Sanidad Municipal que hace hincapié en control de las aguas potables. $\mathbf{N}^{\mathbf{0}} 48$. 